\title{
Does Receiving Clinical Preventive Services Vary across Different Types of Primary Healthcare Organizations? Evidence from a Population-Based Survey
}

La prestation des services préventifs en milieu clinique varie-t-elle selon le type d'organismes offrant des soins de santé primaires? Données provenant d'une enquête auprès de la population

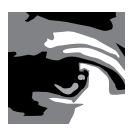

by SYLVIE PROVOST, MSC, MD

Direction de santé publique de l'ASSS de Montréal Institut national de santé publique du Québec Montreal, QC

RAYNALD PINEAULT, MD, PHD

Direction de santé publique de l'ASSS de Montréal Institut national de santé publique du Québec

Centre de recherche du Centre hospitalier de l'Université de Montréal Montreal, QC

JEAN-FRÉDÉRIC LEVESQUE, MD, PHD

Direction de santé publique de l'ASSS de Montréal Institut national de santé publique du Québec

Centre de recherche du Centre hospitalier de l'Université de Montréal Montreal, QC 
Sylvie Provost et al.

STÉPHANE GROULX, MD

Direction de santé publique de l'ASSS de Montérégie

Centre de recherche de l'Hôpital Charles LeMoyne

Longueuil, QC

GENEVIĖVE BARON, MSC, MD

Direction de santé publique de l'ASSS de Montérégie

Centre de recherche de l'Hôpital Charles LeMoyne

Longueuil, QC

DANIĖLE ROBERGE, PHD

Centre de recherche de l'Hôpital Charles LeMoyne

Longueuil, QC

MARJOLAINE HAMEL, MSC

Direction de santé publique de l'ASSS de Montréal

Institut national de santé publique du Québec

Montreal, QC

\begin{abstract}
Objective: To measure the association between primary healthcare (PHC) organizational types and patient coverage for clinical preventive services (CPS).

Method: Study conducted in Quebec (2005), including a population-based survey of patients' experience of care $(\mathrm{N}=4,417)$ and a survey of PHC clinics. Outcome measures: Patient-reported CPS delivery rates and CPS coverage scores. Multiple logistic regressions used to assess factors associated with higher probability of receiving CPS. Results: CPS delivery rates were higher among patients with a regular source of PHC. Higher CPS score was associated with having a public (OR 1.79; 95\% CI 1.35-2.37) or mixed (OR 1.22; 95\% CI 1.01-1.48) type of organization as source of PHC compared to a private one, and having had a high number of visits to the regular source of PHC in the past two years ( $\geq 6$ : OR 1.83 ; 95\% CI 1.41-2.38) compared to a single visit. Conclusion: Public and mixed PHC organizations seem to perform better. CPS delivery is strongly associated with having a regular source of care.
\end{abstract}

\title{
Résumé
}

Objectif: Mesurer la relation entre le type d'organisation de services médicaux de première ligne et la prestation des pratiques cliniques préventives (PCP). Méthodologie : Étude menée au Québec (2005), comprenant une enquête auprès 
de la population sur l'expérience des soins $(\mathrm{n}=4417)$ et une enquête auprès des cliniques de première ligne. Mesures des résultats : Les taux de prestation des PCP rapportés par les patients et le score d'exposition aux PCP. Des régressions logistiques multiples ont été employées pour identifier les facteurs associés à une plus grande probabilité d'être exposé aux PCP.

Résultats: Les taux de prestation des PCP étaient plus élevés chez les patients ayant une source régulière de soins médicaux de première ligne. Un score de PCP plus élevé était associé au fait d'avoir, comme source de soins, un type d'organisation public (RC 1,79; IC $95 \% 1,35-2,37$ ) ou mixte (RC 1,22; IC $95 \% 1,01-1,48$ ), comparé à une organisation privée; et au fait d'avoir eu un nombre élevé de visites à la source régulière de soins au cours des deux années antérieures ( $\geq 6$ visites : RC 1,83; IC $95 \% 1,41$ 2,38), comparé à une seule visite.

Conclusion : Les organisations de soins médicaux de première ligne publiques et mixtes affichent des résultats plus favorables. La prestation des PCP est fortement associée au fait d'avoir une source régulière de soins de première ligne.

I NTEgRATING RECOMMENDED CLINICAL PREVENTIVE SERVICES (CPS) into medical care is recognized as an important component of health systems' response towards chronic illness (Rothman and Wagner 2003; Glasgow et al. 2001). However, current levels of CPS have been deemed suboptimal (Wang et al. 2009; Swan et al. 2003; Ruffin et al. 2000). There are also substantial variations in rates of CPS delivery among clinics and by specific types of CPS (Vogt et al. 2007; Hershey and Karuza 1997). Moreover, there is a lack of consistency between a clinic's performance on one specific CPS and its performance on others (Solberg et al. 2001). Although patient and physician characteristics may influence CPS delivery rate (Flocke et al. 1998b; Pham et al. 2005), having a regular family physician or usual source of primary healthcare (PHC) has a greater impact on the likelihood of receiving preventive services (Schueler et al. 2008; Qi et al. 2006; Starfield et al. 2005; Swan et al. 2003; DeVoe et al. 2003; McIsaac et al. 2001; Flocke et al. 1998b; Bindman et al. 1996). Also, clinical context has an impact on preventive care delivery, CPS being delivered more often during visits for chronic than acute illnesses (Stange et al. 1998; Flocke et al. 1998a) and during visits for routine check-ups than for specific injuries or illnesses (Stange et al. 1994).

With regard to PHC organizational characteristics, studies conducted in the United States indicated that patients receiving PHC in university-based clinics (Ramsey et al. 2001), community health centres (Starfield et al. 2005) or large academic facilities with extensive training programs (Goldzweig et al. 2004) tend to receive more recommended preventive services. In addition, teamwork, common goals shared by physicians and staff, and priority given to prevention have been associ- 
ated with higher CPS delivery (Carpiano et al. 2003). Group practice has also been positively associated with delivery of preventive services (Pham et al. 2005). Thus, it has been advocated that interventions aimed at promoting sustainable CPS delivery should take into account organizational characteristics of PHC settings (Stange et al. 2003; Goodwin et al. 2001).

Integrating CPS into medical practice in the context of PHC reorganization is challenging, and some types of organization may present more favourable conditions for CPS delivery. In Quebec, PHC practice settings include public clinics and privately owned (or "private") clinics. Public clinics include PHC clinics located in Local Community Health Centres (known in Quebec as CLSCs) and in teaching family medicine units (FMUs), where physicians are usually paid on a salary or time basis by the Health Insurance Board, and infrastructure and administrative costs are directly financed by the Ministry of Health (Pineault et al. 2008). In privately owned clinics (groups or solo), physicians are usually paid by the Health Insurance Board on a fee-for-service basis, and infrastructure costs are indirectly paid by the government because they are included in the fees paid to the physicians.

Recent policy reform initiatives by Quebec's Ministry of Health to increase accessibility and continuity of care include the creation of Family Medicine Groups (FMGs). The FMG policy consists mostly in developing a contractual agreement between PHC physicians and the provincial government, including complementary public funding, mostly for computerization and additional staff (nurses), in exchange for increasing services (e.g., extended opening hours). A typical FMG consists of six to 10 physicians working with two nurses to provide services for 10,000 to 20,000 registered patients, by appointment and on a walk-in basis. This new, emerging form of PHC organization can be implemented in various types of clinics (including CLSCs and FMUs). Because FMGs located in privately owned clinics receive direct public funding (e.g., for extra staff and for computerization) in addition to the infrastructure costs indirectly funded by the government through the fee-for-service payment of the physicians, they represent a "mixed" type of PHC organization based on infrastructure and administrative funding.

As Deber (2004) has correctly pointed out, boundaries between public and private are not always clear. The categories described above grossly correspond to the typology developed by Deber in her extensive work, at least for the public and private for-profit small-business types of organizations. As for the mixed type, it contains elements of these two polar cases as there is a direct yet marginal financing that comes from the government, while for the major part it maintains the characteristics of private organizations, both in terms of financing and delivery. Overall, in the two most populous regions of Quebec (Montreal and Monteregie), public clinics represent 13\% of PHC organizations and reach $10 \%$ of patients; private/group type, $53 \%$ of PHC organizations and $65 \%$ of patients; private/solo type, $27 \%$ and $14 \%$ of patients; mixed, $7 \%$ of PHC organizations and $10 \%$ of patients (Pineault et al. 2008). 
Given the gap in knowledge related to the influence of type of PHC organization on clinical preventive services delivery and current $\mathrm{PHC}$ reform, this paper focuses on the association between type of PHC organization and CPS coverage for patients.

\section{Method}

In 2005, a research project (Pineault et al. 2009) conducted in Monteregie, the second most populous region in Quebec, looked at organizational models of PHC delivery and the experience of care of users of these services, including CPS delivery. The project included two surveys: (a) a population-based telephone survey of care experience among randomly selected community-dwelling adults aged 18 and over, using the random-digit dialling method (response rate: 66\%) and (b) a postal survey of all PHC clinics in the region, which focused on their goals and values; material, financial and human resources; current organizational structures; practices supporting service delivery; and inter-organizational collaboration (response rate: $81 \%$ ). The surveys were linked through identification of patients' regular source of care during the past two years. Regular source of care was defined as the place a patient "usually goes to see a doctor for general medical care, excluding specialized care." When respondents did not identify a usual source of care, the place where they went most often in the past two years was designated as the regular source. Among the 4,417 respondents, 3,172 patients had a regular source of PHC (2,618 of them reporting having a family physician within their regular source of care). Respondents who did not answer the questions on CPS $(n=12)$ and those who reported having a family physician outside their regular source of PHC $(n=246)$ were excluded from the analyses.

For the purpose of this paper, the outcome measures were patient-reported CPS delivery rates (data from the population survey). We selected seven services recommended (category A or B) by the Canadian Task Force on Preventive Health Care and the US Preventive Services Task Force at the time of the survey (Table 1). Of the seven CPS, six are in the top 15 ranked by Partnership for Prevention and Health Partners Research Foundation in the United States (Coffield et al. 2001).

An overall CPS coverage score, defined as the proportion of CPS performed among all CPS for which the patient was eligible, was calculated for each respondent using the formula:

Sum of recommended CPS delivered to an individual $\mathrm{X} 100 \%=$ CPS score

Sum of recommended CPS for which an individual is eligible based on age, sex $^{*}$ and lifestyle habits

( ${ }^{*}$ Women who had a hysterectomy were considered ineligible for Pap tests.) 
Sylvie Provost et al.

TABLE 1. Clinical preventive services (CPS) under study

\begin{tabular}{|c|c|c|}
\hline CPS & Time interval for delivery & Target groups \\
\hline Physician recommended a healthy diet & past 2 years & all patients \\
\hline Physician inquired about smoking status & past 2 years & all patients \\
\hline Physician recommended quitting smoking & past 2 years & smokers \\
\hline Physician took blood pressure & past 2 years & all patients \\
\hline Physician did a Pap test & past 3 years & women aged 18-69 \\
\hline Patient had a mammography & past 2 years & women aged 50-69 \\
\hline $\begin{array}{l}\text { Patient had a fecal occult blood test or } \\
\text { sigmoidoscopy/colonoscopy }\end{array}$ & $\begin{array}{l}\text { past } 2 \text { years for fecal occult } \\
\text { blood test } \\
\text { past } 5-10 \text { years for } \\
\text { sigmoidoscopy/colonoscopy }\end{array}$ & patients aged 50 or over \\
\hline
\end{tabular}

In the calculation of CPS scores, missing data, don't know/don't remember responses and refusals for question on a CPS for which the respondent was eligible were included in the "not receiving the CPS" category. Very few of these cases were found (2-20 cases, depending on the CPS).

Four types of PHC organizations were identified from the PHC clinics survey, based on infrastructure and administrative funding as described at the beginning of this paper: two private (group; solo), one public (PHC clinic in a CLSC or FMU) and one mixed (FMG implemented in a private clinic). FMGs implemented in CLSCs or FMUs were included in the public PHC organizations.

A mean CPS score was calculated for respondents pertaining to each type of PHC organization reported as their regular source of care. For each CPS and overall CPS coverage score, multiple logistic regression was used to assess the independent contribution of the type of organization to receiving preventive care (Hosmer and Lemeshow 1989). The CPS score was dichotomized when used as a dependent variable in the logistic regression analysis. A 75\% cut-off was chosen to distinguish individuals with fairly good CPS coverage from the others, based on the distribution of the score and on experts' clinical judgment. Sensitivity analyses using other cut-offs (66\%, 80\% and $100 \%)$ provided similar results. Adjustments were made for potential confounding variables, including socio-demographic characteristics (sex, age, education and income levels) and health status (having risk factors or health problems, smoking status). Time since last visit and number of visits to the regular source in the past two years were also included as predictors in our models. Having a family physician was not included in the regression model because it constitutes an intrinsic characteristic of the types of PHC organizations, and so was considered endogenous. 


\section{Results}

Table 2 presents respondents' socio-demographic and health characteristics by affiliation with a regular source of care. Based on 2001 Canadian census data (2005 projections), our sample was representative of the general population with regard to age and sex. Having a regular source of care is associated with being female, older age, higher educational level, higher income, and having some risk factors or health problems. Among those who had a regular PHC source during the past two years, $60 \%$ had a regular source of PHC in private/group clinics, $20 \%$ in mixed/FMGs, $12 \%$ in private/solo and $8 \%$ in public/CLSC-FMU clinics. A vast majority of respondents had attended their regular source of PHC for at least two years (89\%) and had a family physician within their regular source of care ( $81 \%$ of patients affiliated with private/ group clinics, $83 \%$ with mixed/FMGs, $95 \%$ with private/solo and $78 \%$ with public/ CLSC-FMU clinics). One out of four (24\%) had visited their regular source of PHC six times or more during the past two years.

TABLE 2. Respondent characteristics according to their affiliation with a regular source of PHC: Monteregie, Quebec, Canada, 2005

\begin{tabular}{|l|c|c|c|c|}
\hline & \multicolumn{2}{|c|}{$\begin{array}{c}\text { Respondents with } \\
\text { a regular source } \\
\text { of PHC (N=3, I 72) }\end{array}$} & $\begin{array}{c}\text { Respondents without } \\
\text { a regular source of } \\
\text { PHC (N=987) }\end{array}$ \\
\hline Female & N & \% & N \\
\hline Aged 50 or over & 1,772 & 55.9 & 342 & 34.7 \\
\hline Middle or high level of education & 1,451 & 45.8 & 328 & 33.2 \\
\hline Upper-middle or high income, adjusted for size of household & 1,734 & 54.7 & 481 & 48.8 \\
\hline At least one risk factor (HBP, diabetes, hypercholesterolemia) & 1,254 & 39.5 & 199 & 20.2 \\
\hline At least one health problem (heart, respiratory, stroke, cancer) & 869 & 27.4 & 151 & 15.3 \\
\hline
\end{tabular}

$\mathrm{HBP}=$ high blood pressure

Figure 1 presents patient-reported CPS delivery rates. Rates were higher for all CPS among patients with a regular source of PHC than for those without one. Patient-reported delivery rates also varied depending on the specific CPS. For patients who had a regular source of $\mathrm{PHC}$, rates ranged from $35 \%$ for colorectal cancer screening to $90 \%$ for hypertension screening, and the overall mean CPS coverage score was $63 \%$. Figure 2 shows scores across types of PHC organizations. Scores tend to be higher for patients with a public source of PHC (68\%) than for mixed (64\%), private/ group (61\%) and private/solo clinics (65\%); however, the difference was statistically significant $(p<0.05)$ only between public and private/group PHC organizations. 
Delivery rates of each CPS for each type of PHC clinic (Table 3) show the same pattern: usually higher for public/CLSC-FMU and lower for private/group clinics.

FIGURE 1. Patient-reported CPS delivery (\%): Monteregie, Quebec, Canada, 2005

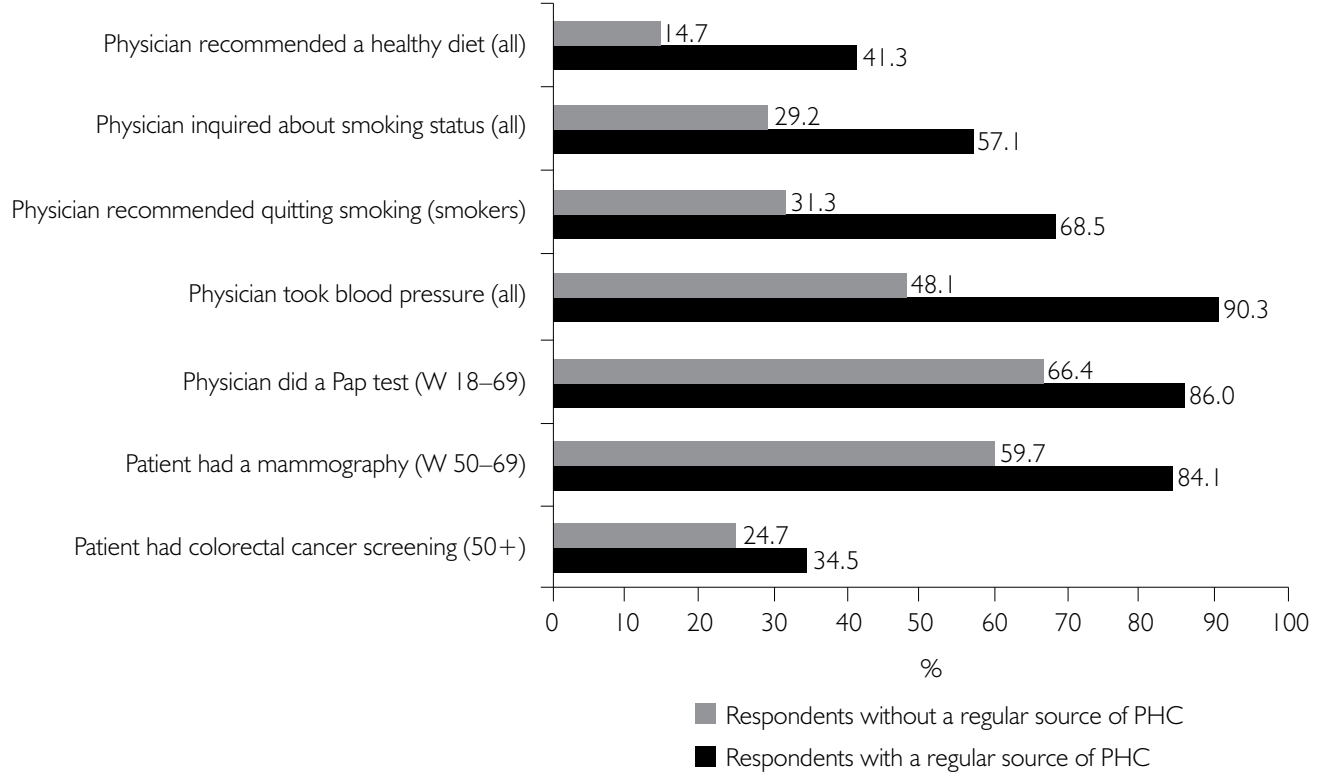

Results of logistic regression analyses (Table 4, see http://www.longwoods.com/ articles/images/22025) indicate that a CPS coverage score $\geq 75 \%$ was associated with having a public (OR 1.79; 95\% CI 1.35-2.37) or mixed (OR 1.22; 95\% CI 1.011.48) source of PHC compared to having a private/group source, and with a high number of visits to the regular source of PHC in the past two years (two to five visits: OR 1.36, 95\% CI 1.08-1.70; six or over: OR 1.83, 95\% CI 1.41-2.38) compared to a single visit. Moreover, association between private/solo clinic and CPS coverage score $\geq 75 \%$ almost reached statistical significance (OR 1.23; 95\% CI 0.97-1.56; $p=0.088$; reference category: private/group). Table 4 also presents the results of logistic regression models using each CPS as the dependent variable. Results show no association between type of clinic and patient-reported rates of nutrition counselling, smoking cessation counselling and mammography. On the other hand, when compared to private/group clinics, smoking status screening was associated with affiliation with public (OR 1.50; 95\% CI 1.12-2.00) and mixed (OR 1.24; 95\% CI 1.02-1.51) clinics; hypertension screening with private/solo clinics (OR 3.18; 95\% CI 1.79-5.64); and colorectal cancer screening with public (OR 3.27;95\% CI 2.15-4.98), private/ solo (OR 1.55; 95\% CI 1.11-2.16) and mixed (OR 1.39; 95\% CI 1.05-1.85) clinics. Association between public clinics and Pap test was near statistical significance (OR 1.85 ; 95\% CI 0.90-3.79; $p=0.09$ ). 
FIGURE 2. Mean CPS score by type of PHC organization: Monteregie, Quebec, Canada, 2005

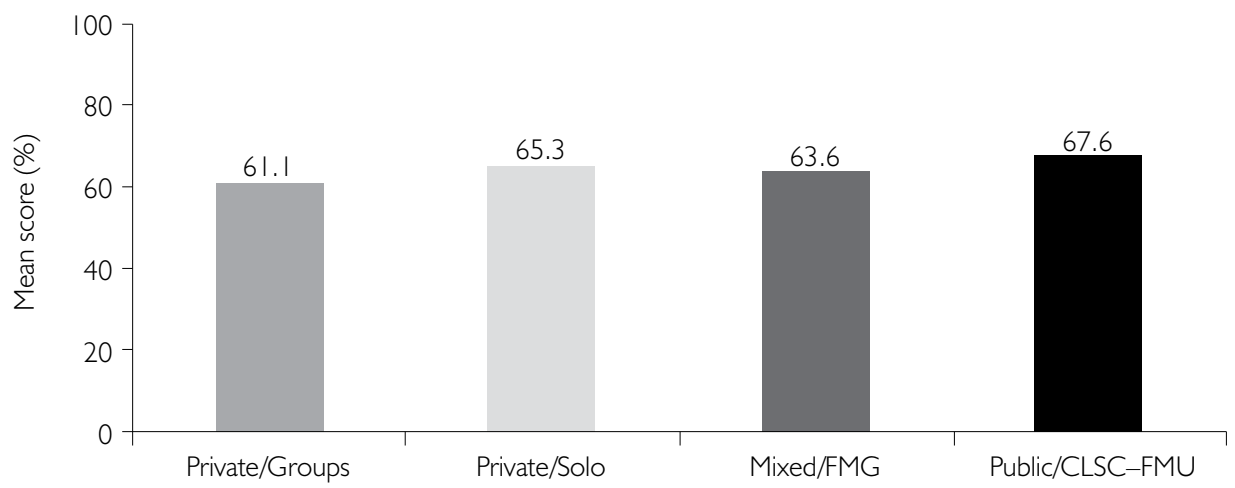

TABLE 3. Patient-reported CPS coverage by type of regular source of PHC. Patients with a regular source of PHC: Monteregie, Quebec, Canada, 2005

\begin{tabular}{|c|c|c|c|c|c|c|c|c|}
\hline 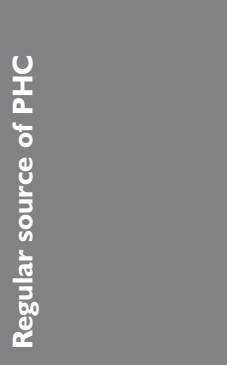 & 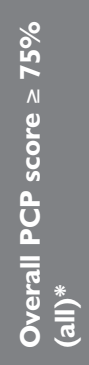 & 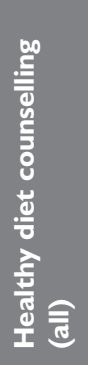 & 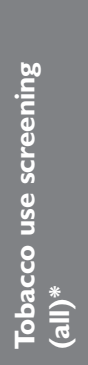 & 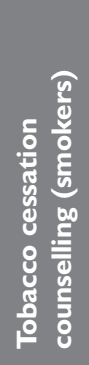 & 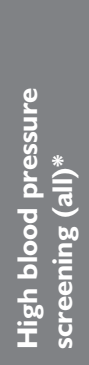 & 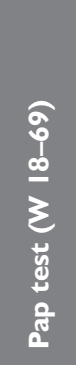 & 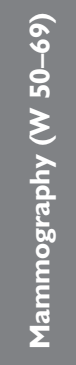 & 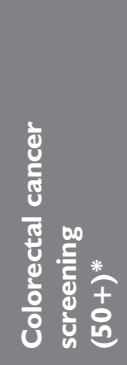 \\
\hline Private/Group & 42.0 & 40.3 & 55.1 & 66.8 & 89.4 & 84.7 & 84.1 & 29.4 \\
\hline Private/Solo & 44.8 & 42.7 & 58.2 & 75.5 & 96.2 & 87.9 & 83.6 & 40.3 \\
\hline Mixed/FMG & 45.3 & 41.9 & 59.4 & 68.6 & 90.5 & 87.1 & 82.8 & 36.6 \\
\hline Public/CLSC-FMU & 55.1 & 44.5 & 64.1 & 70.7 & 88.3 & 91.6 & 87.0 & 58.3 \\
\hline
\end{tabular}

$* p<0.05$

\section{Discussion}

As seen in other studies (Wang et al. 2009; Swan et al. 2003; Ruffin et al. 2000), we found CPS coverage to be suboptimal. However, it seems better for screening (except for colorectal cancer screening) than for lifestyle counselling. Among CPS studied, high blood pressure screening was most frequent, and colorectal cancer screening least frequent, as found by other researchers (Vogt et al. 2007). Variations in CPS delivery at least partly reflect differences inherent in the nature of CPS; some are easier to perform and thus more fully integrated into physicians' practices (e.g., high blood pressure screening); others require more efforts to convince patients to undergo less acceptable and accessible procedures (e.g., colonoscopy) and may be more difficult to implement. 
Some CPS may also be considered closer to the field of clinical medicine (e.g., high blood pressure screening, Pap test) than counselling-type CPS (e.g., recommending a healthy diet). Also, some CPS have been recommended in the medical literature for longer (e.g., hypertension screening) than others (e.g., colorectal screening). Finally, for breast cancer screening, the role of the family physician in Quebec is mainly to reinforce the message of a provincial program that urges eligible women to undergo a mammography every two years.

Our findings confirm that CPS delivery is strongly associated with having a regular source of care, as suggested by other authors (Qi et al. 2006; DeVoe et al. 2003; Flocke et al. 1998b; Bindman et al. 1996). The type of organization of regular PHC source also influences CPS delivery, as better coverage for CPS was more often associated with having public (CLSC, FMU) and mixed (FMG) clinics as regular sources of PHC. The community orientation, greater number of resources and wider range of services in these organizations may enhance preventive services delivery. In addition, these types of organizations are known to have better information and registration systems, enabling health professionals to assess patients' needs for preventive services, and tools to remind clinicians to offer recommending them.

Our findings do not allow us to pinpoint the specific organizational characteristics that might be responsible for differences in CPS delivery across types of clinics. However, in the public PHC organizations in Quebec, physicians are more likely to be paid on a time rather than fee-for-service basis. Fee-for-service paid physicians, that is, most PHC physicians in private types of organizations, do not have separate CPS fees in their reimbursement schedule. Rather, this fee is included in payment for the visit to the PHC physician, a practice that could constitute a disincentive to providing CPS. Physicians in the mixed PHC organizations are mostly paid by feefor-service but also receive, from the Health Insurance Board, fixed annual amounts for each enrolled patient. This per capita component of remuneration may act as an incentive for delivering CPS. As stated by Wee and colleagues (2001) and Gosden and colleagues (2001), studies are needed to examine the effects of financial incentives on quality of care, and whether quality-based incentives improve preventive care performance. Public PHC organizations are also characterized by a clinical orientation that emphasizes prevention and by family medicine training, an approach that may favour integration of CPS delivery into practice. This explanation is supported by Ramsey and colleagues (2001), who found fewer screening services delivered in a county hospital-based clinic than in university-based ones. Organizational characteristics, such as prioritizing prevention, have also been associated with higher CPS delivery rates (Carpiano et al. 2003). Moreover, in public PHC organizations, lower caseloads might free up time to provide more preventive services to fewer patients. However, the higher volume of patients seen in private-group PHC organizations may result in more CPS performed each year, and thus could have a greater impact on the population. 
Further, there is more coverage for CPS in private/solo than private/group clinics. This finding may reflect, at least in part, the importance for CPS coverage of having a family physician, because the private/solo PHC organizations have a higher percentage of patients with regular physicians ( $94.5 \%$ vs. $80.6 \%$ in private/groups). In our bivariate analyses, having a family physician was strongly associated with coverage for CPS $\geq 75 \%$ (unadjusted OR 2.20, 95\% CI 1.81-2.69; data not shown).

Despite the differences we found in patient coverage for recommended CPS across PHC organizations, variations were less extensive than expected. Flocke and Litaker (2007) showed that comparable rates of preventive services delivery occurred across several distinct physician-practice configurations of physician attributes, practice processes and contexts. They suggested that striving for a single, ideal configuration may be less valuable for improving preventive care than understanding and leveraging existing characteristics within PHC practices.

A greater number of visits is also associated with better CPS coverage, presumably related to the higher number of opportunities to address the many curative and preventive concerns (Crabtree et al. 2005; Yarnall et al. 2003; McIsaac et al. 2001; Stange et al. 1998). In our study, there was an association between CPS delivery and number of visits for the overall CPS score as well as for most individual CPS. Although some studies have demonstrated that visiting a regular source of $\mathrm{PHC}$ for a longer time period was associated with delivery of CPS (Parchman and Burge 2004; Steven et al. 1998), others found no association (Pham et al. 2005). Our results do not suggest a clear association between these variables.

\section{Study strengths and limitations}

A major strength of our study is its capacity to establish a link between population and organization survey data, allowing us to link patient-reported CPS delivery to well-characterized PHC organization types. The sample size and relatively good response rates also allow us confidence in our results. However, despite adequate response rates, the paucity of information on non-respondents prevents us from ascertaining the magnitude of bias due to non-response.

The CPS score calculated does not cover the whole range of recommended CPS that should be offered to adult patients. Although it may blur some differences across CPS, the score provides a useful overall comparison measure, across PHC organizations, of a wide array of recommended preventive services that should be offered to the population. Other researchers have used this kind of composite measure (Flocke and Litaker 2007; Nietert et al. 2007; Carpiano et al. 2003; Lemelin et al. 2001; Flocke et al. 1998b). Nietert and colleagues (2007) have stated that the measure calculated for patients can be easily aggregated at higher levels, such as for PHC organizations. Although the overall score may be influenced by the fact that many patients are not 
eligible for all measures (Nietert et al. 2007), including the number of CPS for which patients were eligible as a covariate in regression models did not change the direction or magnitude of our results. Another interesting way to study CPS delivery would be to use a "tracer CPS" that could reflect preventive care delivery as a whole. However, this approach seems unrealistic considering the wide range of preventive interventions, substantial variation among CPS rates, difficulties in selecting a CPS that might reflect differences among physicians' clienteles, and the small correlation observed between a clinic's performance on one preventive service and on others (Solberg et al. 2001). We believe that in addition to analyzing individual services, analysis of CPS delivery using a composite score is appropriate to assess preventive care delivery.

One limitation is the cross-sectional nature of our study, which does not lend itself to causal inference. The study relied on patient self-reported information, which is more susceptible to recall and social desirability biases. Aside from direct observation of medical encounters, a "gold standard" measure of CPS delivery does not exist. Each method of assessing CPS delivery has its advantages and drawbacks. On one hand, chart reviews tend to underestimate CPS delivery compared to physician practice reports through "standardized patient" visits and to physician responses to clinical vignettes (Peabody et al. 2000; Dresselhaus et al. 2000); on the other hand, physician self-reported CPS delivery is frequently overestimated (Montaño and Phillips 1995). Palonen and colleagues (2006) have indicated that medical record reviews and patient surveys provide similar rates of preventive interventions. Moreover, CPS do not represent a homogeneous group of services with regard to evaluation: some, like cancer screening, may be overestimated by patients compared to chart reviews (Wang et al. 2009; Howard et al. 2009; Rauscher et al. 2008; Partin et al. 2008; Khoja et al. 2007; Jones et al. 2008; Hall et al. 2004; McPhee et al. 2002; Hiatt et al. 1995), while others, like lifestyle counselling, may be entered less often in medical charts. Besides, some types of data are more difficult to obtain because of low response rates (e.g., for physician surveys), high costs and confidentiality concerns (e.g., for chart reviews). Finally, administrative data on CPS delivery are not available in Quebec because there is no separate CPS fee in the physicians' reimbursement fee schedules. Patient self-reported data were thus an acceptable proxy for measuring CPS delivery in our study.

Lack of precision in question formulation prevents us from concluding with certainty that CPS were obtained at the patient's regular PHC source. However, although patients could occasionally receive services at other clinics, we assumed that preventive services were more closely associated with their regular source of care. In addition, some CPS (e.g., mammography, sigmoidoscopy/colonoscopy, Pap test) may have been provided as diagnostic procedures rather than for screening purposes. These limitations could overestimate CPS delivery rates by the regular source of PHC. Furthermore, by our limiting coverage for counselling CPS to the past two years, we may have underestimated CPS delivery rates: it is possible that, during the past two years, physicians 
did not consider it pertinent to discuss lifestyle habits again with their long-standing patients. Finally, no information on CPS provided by professionals other than physicians was available in our survey. As CPS delivery may be improved through teamwork involving physicians and other health professionals (Hung 2007; Hung et al. 2006), this information would have been pertinent, because sharing a practice with these professionals is a key feature of new, emerging PHC organizations such as FMGs.

\section{Conclusion}

Our results indicate that CPS delivery in Quebec is strongly associated with having a regular source of care. Regardless of the type of regular PHC source, patient coverage for CPS is not optimal. Public and mixed PHC organizations seem to perform better. Characteristics of these organizations, such as clinical orientation and physicians' method of payment, could explain some of these differences. Further studies designed to identify more precisely the organizational characteristics associated with CPS delivery in PHC settings are needed to help integrate preventive care into practice.

The finding that CPS delivery is associated with continuous care by family physicians raises some concerns in the context of the continuously growing number of interventions expected of them. Consequently, newly emerging PHC organizational models including coordinated teamwork among various types of health professionals could be promising. Further research is needed to study integration of preventive care and reorganization of primary healthcare, taking into account the evolution of organizational models and shared work within PHC teams.

\section{ACKNOWLEDGEMENTS}

Data presented in this paper originate from a research project funded by the Canadian Institutes of Health Research (CIHR), Canadian Health Services Research Foundation (CHSRF) and Fonds de recherche en santé du Québec (FRSQ). Financial support was also provided by the Agence de la santé et des services sociaux (ASSS) de Montréal, Agence de la santé et des services sociaux de la Montérégie, Institut national de santé publique du Québec (INSPQ), Groupe de recherche sur l'équité d'accès et l'organisation des services de santé de première ligne (GRÉAS 1) and Groupe interuniversitaire de recherche sur les urgences (GIRU).

The authors wish to thank André Tremblay (Direction de santé publique de l'ASSS de Montérégie) for his contribution to the construction of the questionnaire, and Alexandre Prud'homme (Direction de santé publique de l'ASSS de Montréal and Institut national de santé publique du Québec) for his contribution to the data analysis.

Correspondence may be directed to: Dr. Sylvie Provost; e-mail: sprovost@santepub-mtl.qc.ca. 
Sylvie Provost et al.

\section{REFERENCES}

Bindman, A.B., K. Grumbach, D. Osmond, K. Vranizan and A.L. Stewart. 1996. "Primary Care and Receipt of Preventive Services." Journal of General Internal Medicine 11(5): 269-76.

Carpiano, R.M., S.A. Flocke, S.H. Frank and K.C. Stange. 2003. "Tools, Teamwork, and Tenacity: An Examination of Family Practice Office System Influences on Preventive Service Delivery." Preventive Medicine 36(2): 131-40.

Coffield, A.B., M.V. Maciosek, J.M. McGinnis, J.R. Harris, M.B. Caldwell, S.M. Teutsch et al. 2001. "Priorities among Recommended Clinical Preventive Services." American Journal of Preventive Medicine 21(1): 1-9.

Crabtree, B.F., W.L. Miller, A.F. Tallia, D.J. Cohen, B. DiCicco-Bloom, H.E. McIlvain, V.A. Aita, J.G. Scott, P.B. Gregory, K.C. Stange and R.R. McDaniel Jr. 2005. "Delivery of Clinical Preventive Services in Family Medicine Offices." Annals of Family Medicine 3(5): 430-35.

Deber, R. 2004. “Delivering Health Care Services: Public, Not-for-Profit, or Private?” In G.P. Marchildon, T. McIntosh and P.-G. Forest, eds., The Fiscal Sustainability of Health Care in Canada: Romanow Papers, Volume 1 (Chapter 7, pp. 233-96). Toronto: University of Toronto Press.

DeVoe, J.E., G.E. Fryer, R. Phillips and L. Green. 2003. "Receipt of Preventive Care among Adults: Insurance Status and Usual Source of Care." American Journal of Public Health 93(5): 786-91.

Dresselhaus, T.R., J.W. Peabody, M. Lee, M.M. Wang and J. Luck. 2000. “Measuring Compliance with Preventive Care Guidelines: Standardized Patients, Clinical Vignettes, and the Medical Record." Journal of General Internal Medicine 15(11): 782-88.

Flocke, S.A. and D. Litaker. 2007. "Physician Practice Patterns and Variation in the Delivery of Preventive Services." Journal of General Internal Medicine 22(2): 191-96.

Flocke, S.A., K.C. Stange and M.A. Goodwin. 1998a. "Patient and Visit Characteristics Associated with Opportunistic Preventive Services Delivery." Journal of Family Practice 47(3): 202-8.

Flocke, S.A., K.C. Stange and S.J. Zyzanski. 1998b. “The Association of Attributes of Primary Care with the Delivery of Clinical Preventive Services." Medical Care 36(8 Suppl.): AS21-30.

Glasgow, R.E., C.T. Orleans and E.H. Wagner. 2001. “Does the Chronic Care Model Serve Also as a Template for Improving Prevention?” Milbank Quarterly 79(4): 579-612.

Goldzweig, C.L., P.H. Parkerton, D.L. Washington, A.B. Lanto and E.M. Yano. 2004. "Primary Care Practice and Facility Quality Orientation: Influence on Breast and Cervical Cancer Screening Rates." American Journal of Managed Care 10(4): 265-72.

Goodwin, M.A., S.J. Zyzanski, S. Zronek, M. Ruhe, S.M. Weyer, N. Konrad, D. Esola and K.C. Stange. 2001. "A Clinical Trial of Tailored Office Systems for Preventive Service Delivery. The Study to Enhance Prevention by Understanding Practice (STEP-UP)." American Journal of Preventive Medicine 21(1): 20-28.

Gosden, T., F. Forland, I.S. Kristiansen, M. Sutton, B. Leese, A. Giuffrida, M. Sergison and L. Pedersen. 2001. "Impact of Payment Method on Behaviour of Primary Care Physicians: A Systematic Review." Journal of Health Services Research and Policy 6(1): 44-55.

Hall, H.I., S.K. Van Den Eeden, D.D. Tolsma, K. Rardin, T. Thompson, A. Hughes Sinclair, D.J. Madlon-Kay and M. Nadel. 2004. "Testing for Prostate and Colorectal Cancer: Comparison of Self-Report and Medical Record Audit." Preventive Medicine 39(1): 27-35. 
Does Receiving Clinical Preventive Services Vary across

Different Types of Primary Healthcare Organizations?

Hershey, C.O. and J. Karuza. 1997. "Assessment of Preventive Health Care: Design

Considerations." Preventive Medicine 26(1): 59-67.

Hiatt, R.A., E.J. Pérez-Stable, C. Quesenberry Jr., F. Sabogal, R. Otero-Sabogal and J. McPhee. 1995. "Agreement between Self-Reported Early Cancer Detection Practices and Medical Audits among Hispanic and Non-Hispanic White Health Plan Members in Northern California." Preventive Medicine 24: 278-85.

Hosmer, D.W. Jr. and S. Lemeshow. 1989. Applied Logistic Regression. New York: John Wiley \& Sons.

Howard, M., G. Agarwal and A. Lytwyn. 2009. "Accuracy of Self-Reports of Pap and Mammography Screening Compared to Medical Record: A Meta-Analysis." Cancer Causes Control 20(1): $1-13$.

Hung, D.Y. 2007. "Improving the Delivery of Preventive Care Services." Managed Care Interface 20(5):38-44.

Hung, D.Y., T.G. Rundall, B.F. Crabtree, A.F. Tallia, D.J. Cohen and H.A. Halpin. 2006.

"Influence of Primary Care Practice and Provider Attributes on Preventive Service Delivery." American Journal of Preventive Medicine 30(5): 413-22.

Jones, R.M., S.J. Mongin, D. Lazovich, T.R. Church and M.W. Yeazel. 2008."Validity of Four Self-Reported Colorectal Cancer Screening Modalities in a General Population: Differences Over Time and by Intervention Assignment." Cancer Epidemiology Biomarkers E Prevention 17(4): 777-84.

Khoja, S., S.E. McGregor and R.J. Hilsden. 2007."Validation of Self-Reported History of Colorectal Cancer Screening." Canadian Family Physician 53(7): 1192-97.

Lemelin, J., W. Hogg and N. Baskerville. 2001. “Evidence to Action: A Tailored Multifaceted Approach to Changing Family Physician Practice Patterns and Improving Preventive Care." Canadian Medical Association Journal 164(6): 757-63.

McIsaac, W.J., E. Fuller-Thomson and Y. Talbot. 2001. “Does Having Regular Care by a Family Physician Improve Preventive Care?" Canadian Family Physician 47: 70-76.

McPhee, S.J., T.T. Nguyen, S.J. Shema, B. Nguyen, C. Somkin, P. Vo and R. Pasick. 2002.

"Validation of Recall of Breast and Cervical Cancer Screening by Women in an Ethnically Diverse Population." Preventive Medicine 35: 463-73.

Montaño, D.E. and W.R. Phillips. 1995. "Cancer Screening by Primary Care Physicians: A Comparison of Rates Obtained from Physician Self-Report, Patient Survey, and Chart Audit." American Journal of Public Health 85(6): 795-800.

Nietert, P.J., A.M. Wessell, R.G. Jenkins, C. Feifer, L.S. Nemeth and S.M. Ornstein. 2007. “Using a Summary Measure for Multiple Quality Indicators in Primary Care: The Summary QUality InDex (SQUID)." Implementation Science 2: 11.

Palonen, K.P., J.J. Allison, G.R. Heudebert, L.L. Willett, C.I. Kiefe, T.C. Wall and T.K. Houston. 2006. "Measuring Resident Physicians' Performance of Preventive Care. Comparing Chart Review with Patient Survey" Journal of General Internal Medicine 21(3): 226-30.

Parchman, M.L. and S.K. Burge. 2004. “The Patient-Physician Relationship, Primary Care Attributes, and Preventive Services." Family Medicine 36(1): 22-27.

Partin, M.R., J. Grill, S. Noorbaloochi, A.A. Powell, D.J. Burgess, S.W. Vernon, K. Halek, J.M. Griffin, M. van Ryn and D.A. Fisher. 2008. "Validation of Self-Reported Colorectal Cancer 
Sylvie Provost et al.

Screening Behavior from a Mixed-Mode Survey of Veterans." Cancer Epidemiology Biomarkers E Prevention 17(4): 768-76.

Peabody, J.W., J. Luck, P. Glassman, T.R. Dresselhaus and M. Lee. 2000. “Comparison of Vignettes, Standardized Patients, and Chart Abstraction: A Prospective Validation Study of 3 Methods for Measuring Quality." Journal of the American Medical Association 283(13): 1715-22.

Pham, H.H., D. Schrag, J.L. Hargraves and B.P. Bach. 2005. “Delivery of Preventive Services to Older Adults by Primary Care Physicians." Journal of the American Medical Association 294(4): 473-81.

Pineault, R., J.F. Levesque, M. Breton, M. Hamel and D. Roberge. 2008. "La Première ligne: quel rôle pour les organisations publiques, privées et mixtes?" In F. Béland et al., eds., Le Privé dans la santé. Montréal: Les Presses de l'Université de Montréal.

Pineault, R., J.F. Levesque, D. Roberge, M. Hamel, P. Lamarche and J. Haggerty. 2009.

"Accessibility and Continuity of Care: A Study of Primary Healthcare in Québec." Research report presented to the Canadian Institutes of Health Research and the Canadian Health Services Research Foundation. Quebec City: Government of Quebec and Centre de recherche de l'Hôpital Charles LeMoyne. ISBN: 978-2-550-55436-3.

Qi, V., S.P. Phillips and W.M. Hopman. 2006. "Determinants of a Healthy Lifestyle and Use of Preventive Screening in Canada." BMC Public Health 6: 275.

Ramsey, S.D., A.D. Cheadle, W.E. Neighbor, E. Gore, P. Temple, T. Staiger and H.I. Goldberg. 2001. "Relative Impact of Patient and Clinic Factors on Adherence to Primary Care Preventive Service Guidelines: An Exploratory Study" Medical Care 39(9): 979-89.

Rauscher, G.H., T.P. Johnson, Y.I. Cho and J.A. Walk. 2008. "Accuracy of Self-Reported CancerScreening Histories: A Meta-Analysis." Cancer Epidemiology Biomarkers E Prevention 17(4): 748-57.

Rothman, A.A. and E.H. Wagner. 2003. “Chronic Illness Management: What Is the Role of Primary Care?” Annals of Internal Medicine 138(3): 256-61.

Ruffin, M.T., D.W. Gorenflo and B. Woodman. 2000. "Predictors of Screening for Breast, Cervical, Colorectal, and Prostatic Cancer among Community-Based Primary Care Practices." Journal of the American Board of Family Practice 13(1): 1-10.

Schueler, K.M., P.W. Chu and R. Smith-Bindman. 2008. "Factors Associated with Mammography Utilization: A Systematic Quantitative Review of the Literature." Journal of Women's Health 17(9): 1477-98.

Solberg, L.I., T.E. Kottke and M.L. Brekke. 2001. "Variation in Clinical Preventive Services." Effective Clinical Practice 4(3): 121-26.

Stange, K.C., T. Fedirko, S.J. Zyzanski and C.R. Jaen. 1994. “How Do Family Physicians Prioritize Delivery of Multiple Preventive Services?" Journal of Family Practice 38(3): 231-37.

Stange, K.C., S.A. Flocke and M.A. Goodwin. 1998. "Opportunistic Preventive Services Delivery. Are Time Limitations and Patient Satisfaction Barriers?" Journal of Family Practice 46(5): 419-24.

Stange, K.C., M.A. Goodwin, S.J. Zyzanski and A.J. Dietrich. 2003. "Sustainability of a PracticeIndividualized Preventive Service Delivery Intervention." American Journal of Preventive Medicine 25(4): 296-300. 
Stange, K.C., S.J. Zyzanski, C.R. Jaen, E.J. Callahan, R.B. Kelly, W.R. Gillanders, J.C. Shank, J. Chao, J.H. Medalie, W.L. Miller, B.F. Crabtree, S.A. Flocke, V.J. Gilchrist, D.M. Langa and M.A. Goodwin. 1998. "Illuminating the 'Black Box': A Description of 4454 Patient Visits to 138 Family Physicians." Journal of Family Practice 46(5): 377-89.

Starfield, B., L. Shi and J. Macinko. 2005. "Contribution of Primary Care to Health Systems and Health." Milbank Quarterly 83(3): 457-502.

Steven, I.D., E. Dickens, S.A. Thomas, C. Browning and E. Eckerman. 1998. "Preventive Care and Continuity of Attendance. Is There a Risk?” Australian Family Physician 27(Suppl. 1): S44-46.

Swan, J., N. Breen, R.J. Coates, B.K. Rimer and N.C. Lee. 2003. "Progress in Cancer Screening Practices in the United States: Results from the 2000 National Health Interview Survey." Cancer 97(6): 1528-40.

Vogt, T.M., A.C. Feldstein, M. Aickin, W.R. Hu and A.R. Uchida. 2007."Electronic Medical Records and Prevention Quality: The Prevention Index." American Journal of Preventive Medicine 33(4): 291-96.

Wang, L., X.N. Jason and R.E. Upshur. 2009. “Determining Use of Preventive Health Care in Ontario: Comparison of Rates of 3 Manoeuvres in Administrative and Survey Data." Canadian Family Physician 55(2): 178-79.

Wee, C.C., R.S. Phillips, H.R. Burstin, E.F. Cook, A.L. Puopolo, T.A. Brennan and J.S. Haas. 2001. "Influence of Financial Productivity Incentives on the Use of Preventive Care." American Journal of Medicine 110(3): 181-87.

Yarnall, K.S., K.I. Pollak, T. Ostbye, K.M. Krause and J.L. Michener. 2003. “Primary Care: Is There Enough Time for Prevention?" American Journal of Public Health 93(4): 635-41. 


\section{Does Receiving Clinical Preventive Services Vary across Different Types of Primary Healthcare Organizations? Evidence from a Population-Based Survey}

La prestation des services préventifs en milieu clinique variet-elle selon le type d'organismes offrant des soins de santé primaires? Données provenant d'une enquête auprès de la population

by SYLVIE PROVOST, RAYNALD PINEAULT, JEAN-FRÉDÉRIC LEVESQUE, STÉPHANE

GROULX, GENEVIĖVE BARON, DANIĖLE ROBERGE AND MARJOLAINE HAMEL

TABLE 4. Factors associated with patient-reported CPS delivery. Patients with a regular source of PHC:

Monteregie, Quebec, Canada, 2005

\begin{tabular}{|c|c|c|c|c|c|c|c|c|c|}
\hline & & 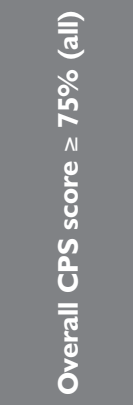 & 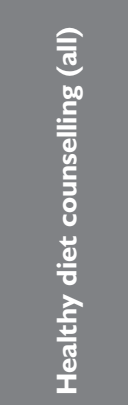 & 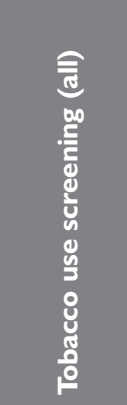 & 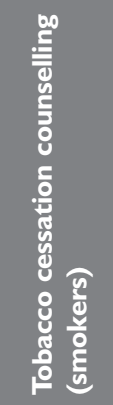 & 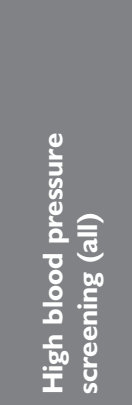 & 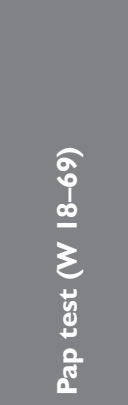 & 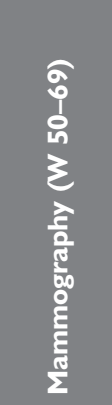 & 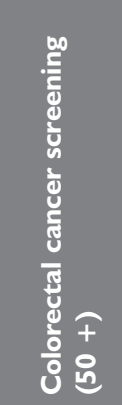 \\
\hline & & $N=3,|6|$ & $N=3,|6|$ & $N=3,|6|$ & $N=923$ & $N=3,|6|$ & $N=1,463$ & $N=695$ & $N=1,44 \mid$ \\
\hline \multicolumn{2}{|c|}{ Independent variables } & $\mathrm{OR}^{+}$ & $\mathrm{OR}^{+}$ & $\mathrm{OR}^{+}$ & $\mathrm{OR}^{+}$ & $\mathrm{OR}^{+}$ & $\mathrm{OR}^{+}$ & $\mathrm{OR}^{+}$ & $\mathrm{OR}^{+}$ \\
\hline \multirow{3}{*}{$\begin{array}{l}\text { Regular source of } \\
\text { PHC (ref.: Private/ } \\
\text { Group) }\end{array}$} & Private/Solo & $1.23 * *$ & 1.08 & $1.28 * *$ & 1.53 & $3.18 *$ & 1.28 & 0.86 & 1.55* \\
\hline & Mixed/FMG & $1.22 *$ & 1.12 & $1.24 *$ & 1.23 & 1.31 & 1.34 & 0.85 & 1.39* \\
\hline & $\begin{array}{l}\text { Public/ } \\
\text { CLSC-FMU }\end{array}$ & 1.79* & 1.22 & 1.50* & 1.23 & 0.91 & $1.85 * *$ & 1.38 & $3.27 *$ \\
\hline $\begin{array}{l}\text { Has been going to } \\
\text { regular source of } \\
\text { PHC (ref.: }<2 \text { years) }\end{array}$ & $\begin{array}{l}2 \text { years } \\
\text { or }+\end{array}$ & 1.09 & 1.00 & 0.83 & 1.04 & 1.10 & 0.66 & $2.73 *$ & 0.91 \\
\hline \multirow{2}{*}{$\begin{array}{l}\text { Visits to regular } \\
\text { source of } \mathrm{PHC} \text {, } \\
\text { past } 2 \text { years (ref.: } \\
\text { I visit) }\end{array}$} & 2 to 5 & 1.36* & $1.25 * *$ & 1.14 & 1.69* & $2.76 *$ & $1.92 *$ & 1.43 & 1.70* \\
\hline & 6 or more & I.83* & 1.69* & 1.33* & $2.45 *$ & $6.42 *$ & 1.30 & 1.22 & $1.67 *$ \\
\hline
\end{tabular}

† OR adjusted for age-sex group, smoking status, level of education, income, risk factors (having high blood pressure, diabetes or hypercholesterolemia), health problems (having heart problems, respiratory problems, stroke or cancer). 